Full length article

\title{
Social network analysis and risk assessment: An example of introducing an exotic animal disease in Italy
}

\author{
Cristiana Maurella ${ }^{\mathrm{a}, *}$, Gianluca Mastrantonio ${ }^{\mathrm{b}}$, Silvia Bertolini ${ }^{\mathrm{a}}$, Maria Ines Crescio ${ }^{\mathrm{a}}$, \\ Francesco Ingravalle ${ }^{\mathrm{a}}$, Amie Adkin ${ }^{\mathrm{c}}$, Robin Simons ${ }^{\mathrm{c}}$, Marco De Nardi ${ }^{\mathrm{d}}$, Augustin Estrada-Peña ${ }^{\mathrm{e}}$, \\ Verity Horigan $^{\mathrm{c}}$, Giuseppe $\mathrm{Ru}^{\mathrm{a}}$ \\ a Istituto Zooprofilattico Sperimentale del Piemonte, Liguria e Valle d'Aosta (IZSPLVA), Italy \\ ${ }^{\mathrm{b}}$ Department of Mathematical science, Polytechnic of Turin, Turin, Italy \\ ${ }^{\mathrm{c}}$ Department of Epidemiological Sciences, Animal and Plant Health Agency, Woodham Lane, New Haw, Surrey, KT15 $3 N B$, UK \\ ${ }^{\mathrm{d}}$ SAFOSO AG, Waldeggstrasse 1, CH3097 Liebefeld, Switzerland \\ e University of Zaragoza (UNIZAR), Spain
}

\section{A R T I C L E I N F O}

\section{Keywords:}

Exposure assessment

Social Network Analysis

Blue Tongue

Spatial distribution

Maps of risk

Exotic disease

\begin{abstract}
A B S T R A C T
Exotic animal diseases are transboundary hazards, characterized by their capability to cover global distances, affecting animal health and welfare with significant economic losses. Their prevention is complex and requires the dynamic management of potential entry points, transmission pathways, and preventative barriers. The welltimed detection of an undefined or unexpected (exotic or re-emerging) threat could minimize the consequences due to onward transmission. As a fit for purpose framework, OIE developed the import risk assessment i.e. a risk assessment model focusing on the entrance of an exotic disease into a geographical area with naïve hosts. In this paper, we propose an improvement of the model by integrating it with Social Network Analysis (SNA) accounting for within-country animal movements. Our integrated model has been used as a combined tool to better estimate the spatial probability of the introduction of at least one affected animal in Italian provinces using Bluetongue (BT) as an example. Starting from international country-specific BT prevalence data, the model estimated the probability of introduction to Italy via two different routes of release i.e. the import of infected animals or the release of infected vectors either associated with imported livestock or through windborne dispersion from Africa. The conventional OIE model estimating the probability of BT entering Italy assuming the same release probability for every Italian province was paralleled by a model integrated with outputs from SNA to account for different release probability among provinces based on animal movements. The conventional model predicted a remarkable homogeneity in the risk among the provinces with some peaks only visible during the warmest months. The model incorporating the network analysis predicted the highest risk to be in the North Eastern region of Italy but also highlighted the likely occurrence in a couple of Southern provinces, an output mirroring past occurrence of BT in Italy. Moreover, the sensitivity analysis highlighted the main role for a couple of model parameters i.e. the probability for a vector to become infected and the vaccine coverage, thus suggesting that an extra effort in vaccine campaigns could be envisaged. The ability to measure animal movements by SNA can allow the identification of geographical risk hot spots and therefore the risk-based targeting of the surveillance system.
\end{abstract}

\section{Introduction}

Exotic animal diseases (EADs) are transboundary hazards, characterized by their capability to cover global distances, affecting animal health and welfare with significant economic losses. Their prevention is complex and requires the dynamic management of potential entry points, transmission pathways and preventative barriers. The well- timed detection of an undefined or unexpected (exotic or re-emerging) threat could minimize the consequences due to onward transmission. Infectious diseases are transmitted among hosts by means of a variety of mechanisms, including direct contact, airborne and vector-borne transmission. The trade of live animals has been demonstrated to be an important mode of transmission for many diseases such as bovine tuberculosis, classical swine fever and Bluetongue (Fevre et al., 2006;

\footnotetext{
* Corresponding author.

E-mail address: cristiana.maurella@izsto.it (C. Maurella).
} 
Bigras-Poulin et al., 2006; Gilbert et al., 2005; Natale et al., 2009; Nöremark et al., 2011). For this reason, livestock movements can be subject to strict controls to reduce the likelihood of disease transmission.

Risk analysis, in an animal health setting, is the formal process of assessing the risks associated with exposure to an imported infective agent (OIE, 2012). The first stage of this step-by-step process is the identification of the hazard, i.e. of the infectious pathogen able to cause adverse health effects in exposed populations; it is considered separately from the subsequent stage which is known as risk assessment. The latter is subdivided into three steps: (1) release (entry) assessment: description of the probable ways to introduce the hazard into a 'free' country; (2) exposure assessment: description of the routes necessary for exposure of animals to the hazard and the quantification of the characteristics and sizes of the exposed populations; (3) consequence assessment: quantification of the consequences, in terms of animal health, economic and environmental effects, occurring after the introduction and the establishment of the hazard (Peeler et al., 2015). The integration of the previous steps produces an overall estimation of the risk (OIE, 2012). A risk assessment model is a model focusing on the entrance of an exotic disease into a geographical area with naïve hosts. The risk assessment may also be performed in cases of sparse data but, in this case, will depend on many assumptions, as well as on subjective choices. For these reasons its success mostly lies in the choice of the most appropriate risk model (Nurminen et al., 1999).

One of the main aims of the collaborative European research project, SPARE, 'Spatial risk assessment framework for assessing exotic disease incursion and spread through Europe' [SPARE, 2016], was to develop a systematic methodology to rank the risk related to selected exotic livestock pathogens based on the probability of incursion and spread within Europe. An effective capability to recognise the emergence of a new or re-emerging disease relies upon a multiagency approach for the detection, diagnosis and surveillance of infectious disease as well as on an integrated methodological approach (King et al., 2004; Blancou et al., 2005; Walsh et al., 2005). With this in mind, focusing on Bluetongue (BT) as an example, we integrated Social Network Analysis (SNA) into the classical exposure pathway used in SPARE with the aim of quantitatively determining the geographical risk of exposure of livestock to an exotic pathogen within Italy.

Social Network Analysis is a technique originally used to investigate the links among local patterns of social relationships within a social structure (Martinez-Lopez et al., 2009). In an epidemiological setting, the description of a social structure provides a flexible framework for investigating associations or interactions within a group. An advantage of the analytical approach of SNA, compared to other techniques, is the ability to handle bi-directional relationships within groups such as contacts among individuals, trade or animal movements. The elements of a network are: the nodes (or vertices or actors) and the connections among the nodes, referred to as edges (or contacts or links). SNA has different ways to be represented: (1) with a graph showing the set of pairs of nodes constituting the network; (2) with a list of the groups of elements and their interactions with a mathematical notation; (3) with the number of contacts represented by an adjacency matrix of $N x N$ nodes, which are the number of contacts among the pairs of nodes in the network (Martinez-Lopez et al., 2009).

Bluetongue is an infectious viral disease transmitted by insect vectors and affecting ruminants. Sheep and goats are the most susceptible species and can show severe clinical symptoms, while in cattle infection is usually asymptomatic. This potentially presents an increased risk for spread of the virus via livestock movements as asymptomatic animals are less likely to be detected and removed from the system (https:// www.gov.uk/government/news/bluetongue-virus-detected-and-dealtwith-in-imported-cattle). BT virus is almost exclusively transmitted by biting midges, such as Culicoides imicola, and the disease is generally considered to be present, or potentially present, in a zone between the $40^{\circ}$ parallel North and the $35^{\circ}$ parallel South, where climatic and environmental conditions are suitable to the vector's life cycle (Giovannini et al., 2004).

The aim of our work was to develop a spatially explicit risk assessment model to better estimate the spatial probability of the introduction of at least one BT affected animal by province within Italy per month. To better estimate spatial heterogeneity at a province level we integrated SNA into the standard risk assessment framework. The model was demonstrated using Italy as a case study but can be applied to any Member State (MS), provided the availability of appropriate animal movement data.

\section{Material and methods}

\subsection{Overview}

The model was based on a classical risk assessment pathway and was developed in R (v3.3.3, http://www.r-project.org/). The framework was modular, and each stage was developed independently with the results of the previous stage acting as the input for the next. The quantitative exposure assessment was stochastic with distributions chosen to best represent the uncertainty in the data.

The inputs for the model were provided by a release assessment developed by Simons et al., described in detail in another paper in this issue (Simons et al., 2018, in this issue). Briefly, the model first estimated the prevalence of the BT in each country of the world, using data from the OIE WAHIS online database (OIE, 2016), then estimated the probability of introduction to Italy via different routes of release. The outputs of the release assessment were, therefore, estimates for the annual release of BT into Italy by route of release. These were expressed in terms of the number of infected animals and of the probability of at least one infected vector incursion. These outputs acted as inputs to the exposure assessment.

The stages of the risk assessment are outlined in Fig. 1. The first step was to determine the number of infected animals and insect vectors (for BT these are midges such as Culicoides imicola) entering the country. The model considered release of BT via livestock movements and windborne dispersion of insect vectors. For the livestock movements, SNA was used to estimate the monthly probability of infected animals going to each province within Italy. For the vector pathway, the release

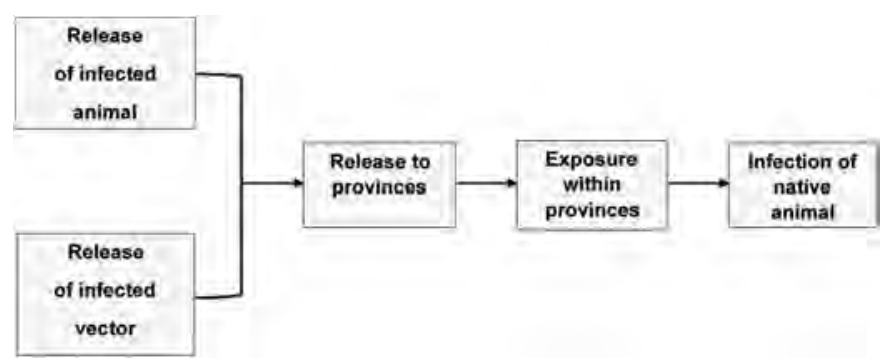

Fig. 1. Model Framework diagram, outlining the stages of the risk assessment. 

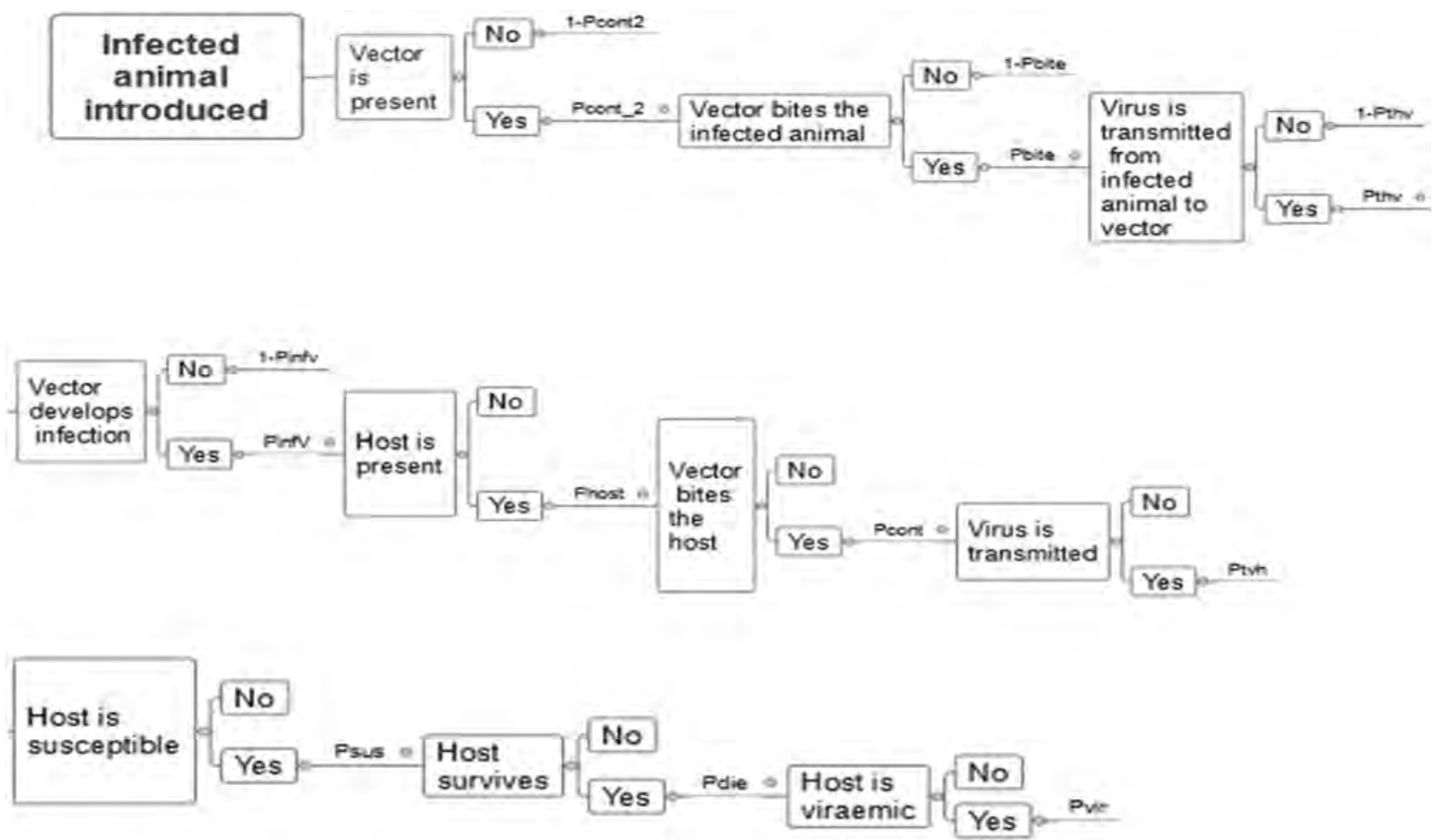

Fig. 2. Pathway of the exposure assessment for Bluetongue infection starting from the probability of introduction of an infected animal.

was equal to the monthly probability of at least one infected vector entering a single Italian province. The exposure assessment then estimated the probability of transmission of the pathogen from the introduced animal (or vector) to the local livestock population. The final output of the model was the probability that at least one autochthonous animal becomes infected from an infected import.

\subsection{Monthly release of infected animals into each province}

The model inputs were the probability that an infected animal was introduced in a year from either the European Union (EU) or extra-EU countries. These probabilities were provided by the quantitative output of the SPARE release assessment model (Simons et al., 2019 in this issue). The following assumptions were made:

1 The probability that an animal is infected is independent of exactly where within a country and when it was imported;

2 The probability of an animal being imported is binomially distributed.

The Italian National Livestock Registry (https://www.vetinfo.sanita.it), provided individual-level data regarding every movement related to trade of sheep, goats and cattle recorded between January 1st, 2013 and December 31st. 2016, on a daily basis. Using this data, we constructed a network that showed the connections among the holdings within a single province for each month. The static network was broken down in monthly representations to identify the changes over time. As this was a direct network, we considered only one measure referring to the number of contacts that each node (i.e., province) received (in-degree).

The objective of the SNA was to estimate the probability of importing at least one infected animal to province $h$ in month $j, P_{j, h}$. Let $n_{i}$ be the expected annual number of infected animals imported to Italy from source $i$, (where $i=1$ for EU countries and $i=2$ for Extra-EU countries) given by outputs from the release assessment, and $m_{i}$ be the expected total number of animals imported to Italy, obtained from the livestock registry. Then, the estimated prevalence of infection amongst imported animals, $p_{i}$, was given by $p_{i}=n_{i} / m_{i}$. Assuming no differences due to seasonality or Italian provinces, other than the number of animals imported, then the probability of at least one infected animal imported into province $h$ in month $j$ from source $i, p_{i, j, h}$, was given by

$p_{i, j, h}=1-\left(1-p_{i}\right)^{\wedge} m_{i, j, h}$

The final probability $P_{j, h}$ was obtained by summing over the sources:

$P_{j, h}=\sum_{i=1}^{2} p_{i, j, h}\left(\frac{m_{i, j, h}}{m_{1, j, h}+m_{2, j, h}}\right)$

where $\left(\frac{m_{i, j, h}}{m_{1, j, h}+\left(m_{2, j, h}\right)}\right)$ is the probability that the infected animal is imported from source $i$. Notice that $P_{j, h}$ is the marginal distribution to have an infected case, independently from the source, and it is the sum of the conditional probabilities to have an infected case from source $i$, multiplied by the probability that an animal is imported from source $i$. 

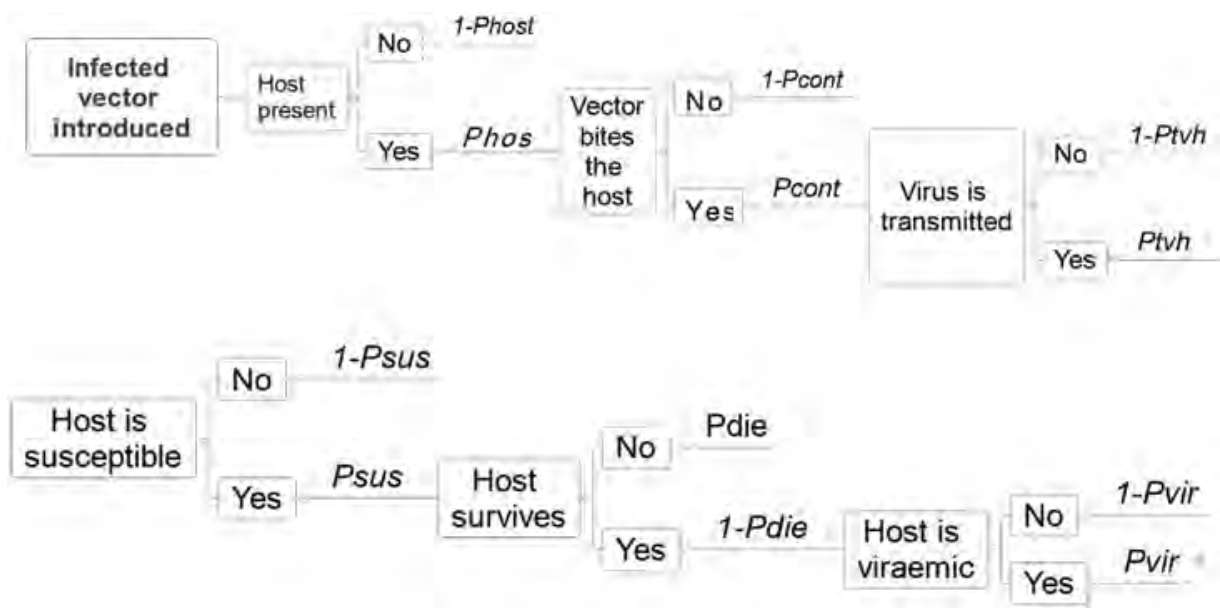

Fig. 3. Pathway of the exposure assessment for Bluetongue infection starting from the probability of introduction of at least an infected vector.

\subsection{Monthly release of infected vectors into each province}

The model considers two routes by which infected vectors may enter Italy: via livestock and via windborne dispersion from Africa. For the livestock route, the model assumes movement of vectors occurs together with the trade of animals and so the same SNA model as used for release of infected animals can be used. Thus the probability of introduction of at least one infected vector is the same as the probability of introduction of at least one infected cattle, $P_{j, h}$.

For the windborne dispersion route, it was assumed that infected vectors can travel from the north coast of Africa into Italian provinces. It was further assumed that the closer the province to Africa, the more vectors can reach it. Due to limited data, the probability of release of infected vectors was not explicitly calculated, but we performed the model starting from a single infected vector.

\subsection{Exposure pathway}

A scenario tree detailing the most likely exposure pathway for BT within an Italian province was developed along with the equations and their most appropriate parametrisation based on available data, incorporating variability and/or uncertainty where relevant. The exposure pathway was split into two: one starting from an infected ruminant introduced into an Italian farm (Fig. 2), and the second starting from an infected vector which enters Italy (Fig. 3). To quantify the risk, we input a value for each single step included in the pathways (Tables $1 \mathrm{a}$ and $1 \mathrm{~b})$. We did not differentiate among different BT serotypes.

The probability that an autochthonous animal gets infected in province $h$ and month $j$ from the introduction of an infected animal, $P_{\text {inf }, j, h \text {, }}$ is given by

$P_{\text {inf }, j, h}=P_{j, h} P_{v i r, j, h}$

where $P_{j, h}$ is the probability of importing at least one infected animal to province $h$ in month $j$ and $P_{v i r, j, h}$ is the probability that an autochthonous animal in province $h$ in month $j$ is infected, given that an infected animal is introduced. The probability $P_{v i r, j, h}$ is given by a stochastic implementation of the scenario trees in Figs. 2 and 3.

\subsection{Exposure via infected vector}

Starting from previous research suggesting that the maximum distance covered by a Culicoides is equal to $700 \mathrm{~km}$ (Sellers, 1992; Roberts et al., 2016), we considered the distance between Africa and Italy thus: the probability of an infected vector arriving in Italy from Africa, $E f A f_{h}$, was described by a decreasing function of the distance,

$\operatorname{EfAf}_{h}=\max \left(1 ; 0-\left(\frac{1}{700}\right) * d_{A, h}\right) * 0.0002$,

where $d_{A, h}$ is the minimum distance (in kilometres) between Africa and province $h$ and 0.0002 is an estimate of the seroprevalence of BT virus in midges in Africa (Savini et al., 2005).

The probability at least one animal becomes infected in area $h$ from the introduction of an infected vector, $P_{\text {final, } j, h}$, is given by

$P_{\text {final }, j, h}=0.5^{*} E f A f_{h}+0.5^{*} P_{v i r, j, h} P_{j, h}$.

Probability $P_{\text {final }, j, h}$ is a weighted sum between the two components (i.e. the probability that an autochthonous animal gets infected in province $h$ and month $j$ from the introduction of an infected animal plus the distance from Africa), where the weights are both equal to 0.5 and it is the probability that when an infected vector enters Italy, it comes from Africa.

\subsection{Outputs}

We produced maps for the exposure assessment model for BT in Italian provinces, starting from the release of one infected animal or from the introduction of an infected vector. Here only the latter is reported.

The uncertainty of the model for each of the geographical units is presented by means of a scatterplot of each monthly mean value and the $95 \%$ Credible Interval $(95 \% \mathrm{CI})$. 
Table 1a

List of the inputs and their parameterization used to specify the exposure pathway starting from the probability of introduction of an infected animal. ** $=$ Minimum and Maximum of the monthly Temperature for single province.

\begin{tabular}{|c|c|c|c|}
\hline $\begin{array}{l}\text { Ind- } \\
\text { ex }\end{array}$ & Description & Value & References (source of data) \\
\hline & Annual number of infected animals imported & Release output & \\
\hline $\mathrm{C} 2$ & Temperature & $\mathrm{C} 2 \sim$ Uniform $\left(\mathrm{a}_{2}, \mathrm{~b}_{2}\right) \mathrm{a}_{2}=22 \mathrm{~b}_{2}=25$ & http://www.worldclim.org/ \\
\hline C3 & Area of province & Fixed value (variable among provinces) & https://ec.europa.eu/eurostat/data/database \\
\hline $\mathrm{C} 4$ & Number of hosts & Fixed value (variable among provinces) & National Cattle Registry (https://www.vetinfo.it/) \\
\hline C5 & Number of farms & Fixed value (variable among provinces) & National Cattle Registry (https://www.vetinfo.it/) \\
\hline C6 & Host density (cattle) $/ \mathrm{Km}^{2}$ & $\mathrm{C} 4 / \mathrm{C} 3$ & National Cattle Registry (https://www.vetinfo.it/) \\
\hline C7 & Farm density (farm $/ \mathrm{Km}^{2}$ ) & $\mathrm{C} 5 / \mathrm{C} 3$ & National Cattle Registry (https://www.vetinfo.it/) \\
\hline $\mathrm{C} 8$ & Host per farm & $\mathrm{C} 4 / \mathrm{C} 5$ & National Cattle Registry (https://www.vetinfo.it/) \\
\hline C9 & Probability of at least one farm $/ \mathrm{Km}^{2}$ & C9 $\sim \operatorname{LogNormal}\left(\mu_{9}, \sigma_{9}\right) \mu_{9} \sim \operatorname{Poisson}(C 7) \sigma_{9}^{2}=1$ & \\
\hline $\mathrm{C} 10$ & Probability of at least one head of cattle in a farm $/ \mathrm{Km}^{2}$ & $\mathrm{C} 10 \sim \mathrm{C} 9 *(1-$ Poisson(C8) $)$ & \\
\hline $\mathrm{C} 11$ & Vector density $/ \mathrm{Km}^{2}$ & $\operatorname{C} 11 \sim \operatorname{LogNormal}\left(\mu_{11}, \sigma_{11}\right) \mu_{11}=750, \sigma_{11}^{2}=2$ & Assumption \\
\hline $\mathrm{C} 12$ & Days of life for a vector & $=111.84 * \operatorname{EXP}(-0.1547 * \mathrm{C} 2)$ & Gerry and Mullens, 2000 \\
\hline C13 & Spread $(\mathrm{Km})$ of a vector in a week & $\operatorname{C13} \sim \operatorname{LogNormal}\left(\mu_{12}, \sigma_{12}\right) \mu_{12}=10 \sigma_{12}^{2}=1$ & $\begin{array}{l}\text { https://assets.publishing.service.gov.uk/government/ } \\
\text { uploads/system/uploads/attachment_data/file/714607/ } \\
\text { qra-BTV8-UK-160212.pdf }\end{array}$ \\
\hline C14 & Spread $(\mathrm{Km})$ of a vector in a day & $\mathrm{C} 13 / 7$ & \\
\hline $\mathrm{C} 15$ & Probability of contact farm/vector & $=1-\left(\left((1-\mathrm{C} 10)^{\wedge} \mathrm{C} 14\right)^{\wedge} \mathrm{C} 12\right)$ & \\
\hline C16 & Incidence of infected farms & $1 / \mathrm{C} 5$ & \\
\hline C17 & Expected number of contacted farms by vectors & $\mathrm{C} 15^{*} \mathrm{C} 7 * \mathrm{C} 3$ & \\
\hline $\mathrm{C} 18$ & $\begin{array}{l}\text { Probability that at least one vector contacts the only } \\
\text { infected farm }\end{array}$ & C30 1-Binomial(C19, C16) & \\
\hline C19 & Expected number of vectors for each farm & $\mathrm{C} 11 * \mathrm{C} 3 / \mathrm{C} 17$ & Discontools (https://www.discontools.eu/database.html) \\
\hline $\mathrm{C} 20$ & Incidence within the farm & $1 / \mathrm{C} 8$ & \\
\hline $\mathrm{C} 21$ & $\begin{array}{l}\text { Probability that at least one vector contacts the only } \\
\text { infected head }\end{array}$ & C21 1-Binomial(C19;C16) & \\
\hline $\mathrm{C} 22$ & Vector daily probability of feeding & $\begin{array}{l}\text { 1-EXP }(-0.000171 * C 2 *(C 2-3.6966) *(41.8699-C 2) \\
\wedge(1 / 2.7056))\end{array}$ & Gerry and Mullens, 2000 \\
\hline $\mathrm{C} 23$ & Probability that a vector bites the only infected head & $\mathrm{C} 22 * \mathrm{C} 23$ & \\
\hline $\mathrm{C} 24$ & Probability of transmission from host to vector & 0.075 & Guis et al., 2011; Nunamaker et al., 1997 \\
\hline $\mathrm{C} 25$ & Probability of transmission $\mathrm{h}_{-} \mathrm{v}$ & $\mathrm{C} 21 * \mathrm{C} 23 * \mathrm{C} 24$ & \\
\hline $\mathrm{C} 26$ & Probability for a vector to become infectious & $\begin{array}{l}C 26-\operatorname{Beta}\left(a_{26}, b_{26}\right) a_{26} b_{26} \text { estimated based on a } \\
\text { distribution having } \\
\text { mean }=1-\operatorname{EXP}(-0.0003 * C 2 *(C 2-10.4)) \text { and } \\
\text { variance }=0.01\end{array}$ & Hartemink et al., 2009 \\
\hline C27 & Probability of vector infection from cattle & $\mathrm{C} 25 * \mathrm{C} 26$ & \\
\hline $\mathrm{C} 28$ & Probability of at least one ruminant in a farm $/ \mathrm{km}^{2}$ & C28 (1-Poisson(C8) & \\
\hline $\mathrm{C} 29$ & Probability of contact farm/vector & $1-\left(\left((1-\mathrm{C} 28)^{*} \mathrm{C} 14\right)^{\wedge} \mathrm{C} 12\right)$ & \\
\hline C30 & Probability of transmission $v->h$ & 1 & \\
\hline C31 & Probability of viral transmission to the host & $=\mathrm{C} 23 * \mathrm{C} 30 * \mathrm{C} 29$ & \\
\hline $\mathrm{C} 32$ & Vaccine coverage ruminants & $\begin{array}{l}\mathrm{C} 32 \sim \operatorname{Beta}\left(\mathrm{a}_{32}, \mathrm{~b}_{32}\right) \mathrm{a}_{32} \mathrm{~b}_{32} \text { estimated based on a } \\
\text { distribution having mean }=0.26 \text { and } \\
\text { variance }=0.01\end{array}$ & $\begin{array}{l}\text { https://bluetongue.izs.it/j6_bluetongue/resources/pdf/ } \\
\text { docTecnici/vaccino/vaccini.pdf;jsessionid= } \\
\text { D85D7BB295CBC17DA0ED96DDFB033FA1.tomcatprod1 }\end{array}$ \\
\hline C33 & Vaccine efficacy & 1 & \\
\hline C34 & Probability of a susceptible cattle & $1-(\mathrm{C} 17 * \mathrm{C} 18)$ & Guis et al., 2011 \\
\hline C35 & Probability for susceptible cattle to develop infection & 1 & \\
\hline C36 & Probability of dying (cow) & $\mathrm{C} 36 \sim$ Uniform $\left(\mathrm{a}_{32}, \mathrm{~b}_{32}\right) \mathrm{a}_{32}=0 \mathrm{~b}_{32}=1 \mathrm{e}-04$ & Bluetongue entomologic surveillance Italy \\
\hline C37 & Probability of viremia & $(1-\mathrm{C} 36) * \mathrm{C} 31 * \mathrm{C} 34 * \mathrm{C} 35$ & \\
\hline $\mathrm{C} 38$ & Duration of infection (Dinf) cattle & $\operatorname{C} 38 \sim \operatorname{LogNormal}\left(\mu_{38}, \sigma_{38}\right) \mu_{38}=16.4 \sigma_{38}^{2}=1$ & Guis et al., 2011; Nunamaker et al., 1997 \\
\hline C39 & Probability of a susceptible ruminant to be viraemic & $\left(1-(1-\mathrm{C} 37)^{\wedge} \mathrm{C} 38\right)$ & \\
\hline
\end{tabular}

To visually compare the results of our framework model with the real occurrence of the disease we obtained the number and the map reference points of BT outbreaks occurring in Italy from the official database of the Ministry of Health (https://www.vetinfo.sanita.it/) from the 1st of January 2016 to the 30th of April 2018.

\subsection{Sensitivity analysis}

Sensitivity analysis of the stochastic model parameters (i.e. the index values of the Tables 1a and 1b: C2 = Temperature; C11 = Day life of a vector; $\mathrm{C} 12=$ Spread of a vector in a week; $\mathrm{C} 18=$ Vaccine coverage; C22 = Probability of dying; C24 = Duration of infection;

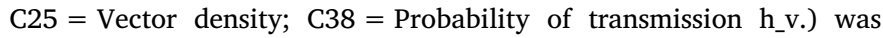
done using a one-way analysis of variance (ANOVA) approach (Frey and Patil, 2002; Patil and Frey, 2004). This is a standard statistical methodology that has been used in previous risk assessments (Adkin et al., 2016; Simons et al., 2016). Briefly, for each iteration $y$ of the model the ANOVA analysis compares a point estimate of the input 
Table 1b

List of the inputs and their parameterization used to specify the exposure pathway starting from the probability of introduction of at least an infected vector.

\begin{tabular}{|c|c|c|c|}
\hline Index & Description & Value & Reference (source of data) \\
\hline & Probability of release at least one infected vector & Release output & \\
\hline $\mathrm{C} 2$ & Temperature & $\mathrm{C} 2 \sim \operatorname{Uniform}\left(a_{2}, b_{2}\right), a_{2}=22 b_{2}=25$ & http://www.worldclim.org/ \\
\hline $\mathrm{C} 3$ & Area of province $\left(\mathrm{km}^{2}\right)$ & Fixed Value (variable among provinces) & https://ec.europa.eu/eurostat/data/database \\
\hline $\mathrm{C} 4$ & Number of hosts & Fixed Value (variable among provinces) & National Cattle Registry (https://www.vetinfo.it/) \\
\hline C5 & Number of farms & Fixed Value (variable among provinces) & National Cattle Registry (https://www.vetinfo.it/) \\
\hline C6 & Host density (cattle)/Km2 & $\mathrm{C} 4 / \mathrm{C} 3$ & National Cattle Registry (https://www.vetinfo.it/) \\
\hline C7 & Farm density (farm/Km2) & $\mathrm{C} 5 / \mathrm{C} 3$ & National Cattle Registry (https://www.vetinfo.it/) \\
\hline $\mathrm{C} 8$ & Host per farm & $\mathrm{C} 4 / \mathrm{C} 5$ & National Cattle Registry (https://www.vetinfo.it/) \\
\hline C9 & Probability of at least one farm/Km2 & C9 $\sim \operatorname{LogNormal}\left(\mu_{9}, \sigma_{9}\right), \mu_{9} \sim \operatorname{Poisson}(\mathrm{C} 7), \sigma_{9}^{2}=1$ & \\
\hline $\mathrm{C} 10$ & Probability of at least one head of cattle in a farm $/ \mathrm{Km} 2$ & $\mathrm{C} 10 \sim \mathrm{C} 9 *(1-\mathrm{Poisson}(\mathrm{C} 8))$ & \\
\hline C11 & Days of life for a vector & $=111.84 * \operatorname{EXP}(-0.1547 * \mathrm{C} 2)$ & Gerry and Mullens, 2000 \\
\hline $\mathrm{C} 12$ & Spread $(\mathrm{Km})$ of a vector in a week & C12 $\sim \operatorname{LogNormal}\left(\mu_{12}, \sigma_{12}\right), \mu_{12}=10 \sigma_{12}^{2}=1$ & $\begin{array}{l}\text { https://assets.publishing.service.gov.uk/government/ } \\
\text { uploads/system/uploads/attachment_data/file/714607/ } \\
\text { qra-BTV8-UK-160212.pdf }\end{array}$ \\
\hline $\mathrm{C} 13$ & Spread $(\mathrm{Km})$ of a vector in a day & $\mathrm{C} 12 / 7$ & \\
\hline $\mathrm{C} 14$ & Probability of contact farm/vector & $1-\left(\left((1-\mathrm{C} 10)^{\wedge} \mathrm{C} 13\right)^{\wedge} \mathrm{C} 11\right)$ & \\
\hline $\mathrm{C} 15$ & Vector daily probability of biting an host & $\begin{array}{l}1-\mathrm{EXP}(-0.000171 * \mathrm{C} 2 *(\mathrm{C} 2-3.6966) *(41.8699-\mathrm{C} 2) \\
(1 / 2.7056))\end{array}$ & Gerry and Mullens, 2000 \\
\hline C16 & Probability of transmission vector to host & ( & Discontools (https://www.discontools.eu/database.html) \\
\hline $\mathrm{C} 17$ & Probability of viral transmission to the host & $=\mathrm{C} 15 * \mathrm{C} 16 * \mathrm{C} 14$ & \\
\hline C18 & Vaccine coverage cattle & $\begin{array}{l}\mathrm{C} 18 \sim \operatorname{Beta}\left(\mathrm{a}_{18}, \mathrm{~b}_{18}\right), \mathrm{a}_{18}, \mathrm{~b}_{18} \text { estimated based on the } \\
\text { distribution having mean }=0.26 \text {, variance }=0.01\end{array}$ & $\begin{array}{l}\text { https://bluetongue.izs.it/j6_bluetongue/resources/pdf/ } \\
\text { docTecnici/vaccino/vaccini.pdf;jsessionid = } \\
\text { D85D7BB295CBC17DA0ED96DDFB033FA1.tomcatprod1 }\end{array}$ \\
\hline C19 & Vaccine efficacy & 1 & \\
\hline $\mathrm{C} 20$ & Probability of a susceptible cattle & $1-(\mathrm{C} 18 * \mathrm{C} 19)$ & \\
\hline $\mathrm{C} 21$ & Probability for susceptible cattle to develop infection & 1 & Discontools (https://www.discontools.eu/database.html) \\
\hline $\mathrm{C} 22$ & Probability of dying (cow) & $\mathrm{C} 22 \sim$ Uniform $\left(a_{22}, b_{22}\right), a_{22}=0, b_{22}=1 \mathrm{e}-04$ & \\
\hline $\mathrm{C} 23$ & Probability of viremia (Pvir) cattle & $(1-\mathrm{C} 22) * \mathrm{C} 17 * \mathrm{C} 20 * \mathrm{C} 21$ & \\
\hline $\mathrm{C} 24$ & Duration of infection (Dinf) cattle & $\mathrm{C} 24 \sim \operatorname{LogNormal}\left(\mu_{24}, \sigma_{24}\right), \mu_{24}=20.6 \sigma_{24}^{2}=1$ & Guis et al., 2011 \\
\hline $\mathrm{C} 25$ & Probability of a susceptible cattle to be viraemic & $\left(1-(1-\mathrm{C} 23)^{\wedge} \mathrm{C} 24\right)$ & \\
\hline $\mathrm{C} 26$ & Vector density/Km2 & $\operatorname{C} 26 \sim \operatorname{LogNormal}\left(\mu_{26}, \sigma_{26}\right), \mu_{26}=750 \sigma_{24}^{2}=2$ & Assumption \\
\hline $\mathrm{C} 27$ & Probability of contact farm/vector & $1-(1-\mathrm{C} 14)^{\wedge} \mathrm{C} 26$ & \\
\hline $\mathrm{C} 28$ & Incidence of infected farm & $1 / \mathrm{C} 5$ & \\
\hline $\mathrm{C} 29$ & Expected number of contacted farms by vectors & $\mathrm{C} 27 * \mathrm{C} 7 * \mathrm{C} 3$ & \\
\hline $\mathrm{C} 30$ & $\begin{array}{l}\text { Probability that at least one vector contacts the only } \\
\text { infected farm }\end{array}$ & C30 1-Binomial $(\mathrm{C} 29, \mathrm{C} 28)$ & \\
\hline C31 & Expected number of vectors for each farm & $\mathrm{C} 26 * \mathrm{C} 3 / \mathrm{C} 29$ & \\
\hline C32 & Incidence within the farm & $1 / \mathrm{C} 8$ & \\
\hline C33 & $\begin{array}{l}\text { Probability that at least one vector contacts the only } \\
\text { infected head }\end{array}$ & C33 1-Binomial $(\mathrm{C} 31, \mathrm{C} 32)$ & \\
\hline C34 & Vector daily probability of feeding & $\begin{array}{l}1-\mathrm{EXP}(-0.000171 * \mathrm{C} 2 *(\mathrm{C} 2-3.6966) *(41.8699-\mathrm{C} 2) \\
(1 / 2.7056))\end{array}$ & Gerry and Mullens, 2000 \\
\hline C35 & Probability that a vector bites the only infected head & $\mathrm{C} 33 * \mathrm{C} 34$ & \\
\hline C36 & Probability of cattle to transmit infection & $\mathrm{C} 25^{*}(1-\mathrm{C} 22)$ & \\
\hline C37 & Probability of transmission from host to vector & 0.075 & Guis et al., 2011; Nunamaker et al., 1997 \\
\hline C38 & Probability of transmission $h_{-} v$ & $\mathrm{C} 35^{*} \mathrm{C} 36 * \mathrm{C} 37$ & \\
\hline C39 & Probability for a vector to become infectious & $\begin{array}{l}C 39 \sim \operatorname{Beta}\left(a_{39}, b_{39}\right), a_{39}, b_{39} \text { estimated based on the } \\
\text { distribution having } \\
\text { mean }=1-\mathrm{EXP}\left(-0.0003^{*} \mathrm{C} 2 *(\mathrm{C} 2-10.4)\right) \text { and } \\
\text { variance }=0.01\end{array}$ & Hartemink et al., 2009 \\
\hline $\mathrm{C} 40$ & Probability of vector infection from cattle & $\mathrm{C} 38 * \mathrm{C} 39$ & \\
\hline
\end{tabular}

parameter value against the value of a 'response' variable, returning an $F$ value which provides a measure of the extent to which the two are correlated. In this analysis the response variable is the final probability to have at least one autochthonous infection. We conduct independent analyses for two provinces at high risk, Agrigento and Padova, and for the two months at highest risk, July and August.

\section{Results}

The network built from the trade data is shown in the Fig. 4. This figure shows that majority of animals entering Italy go to provinces in the North West.

The map of the probability of the introduction of BT into Italy without taking into account the trade of livestock, i.e. for vector release only, is shown in Fig. 5. This suggests that the highest probability is in July and August in the southern provinces of Lecce and Taranto.

The median probability of having an autochthonous case represented by the final output of the parameterized model integrated with the SNA is shown in the Fig. 6 . In this figure we see that the highest probability of having an autochthonous case is in North West 

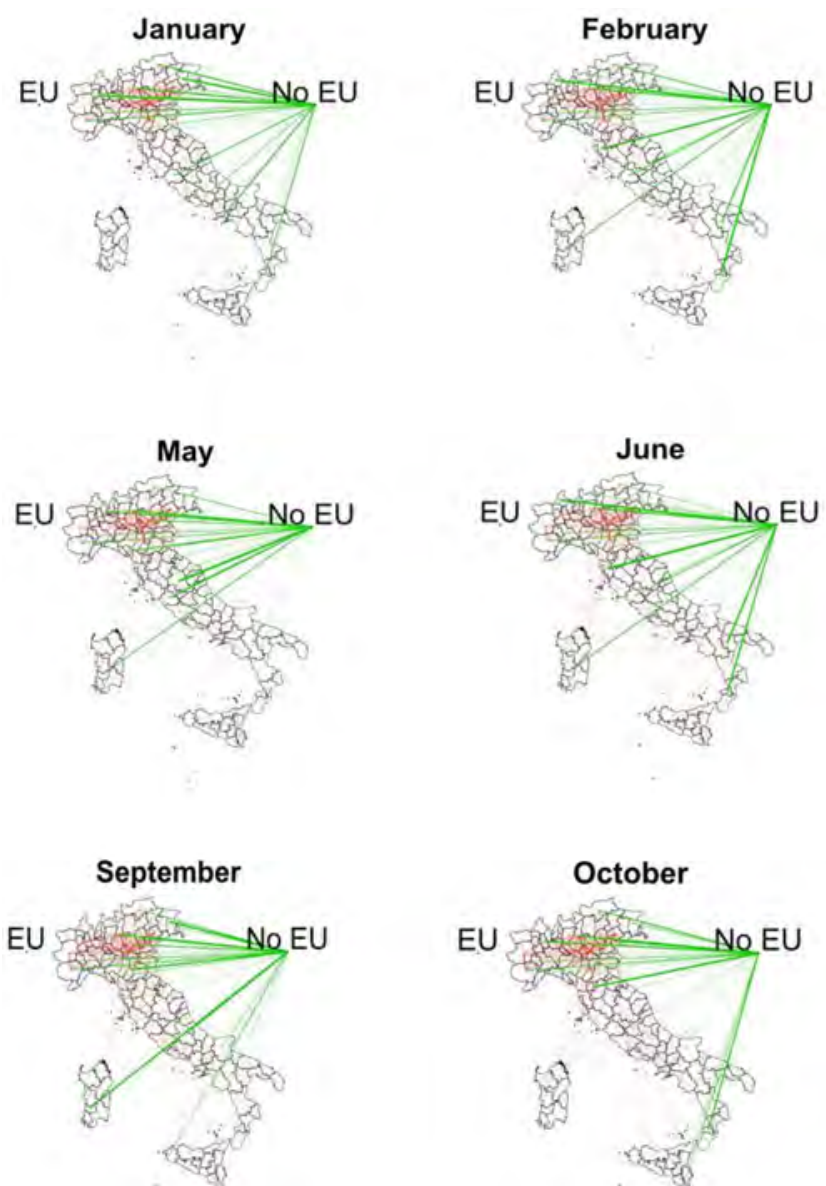
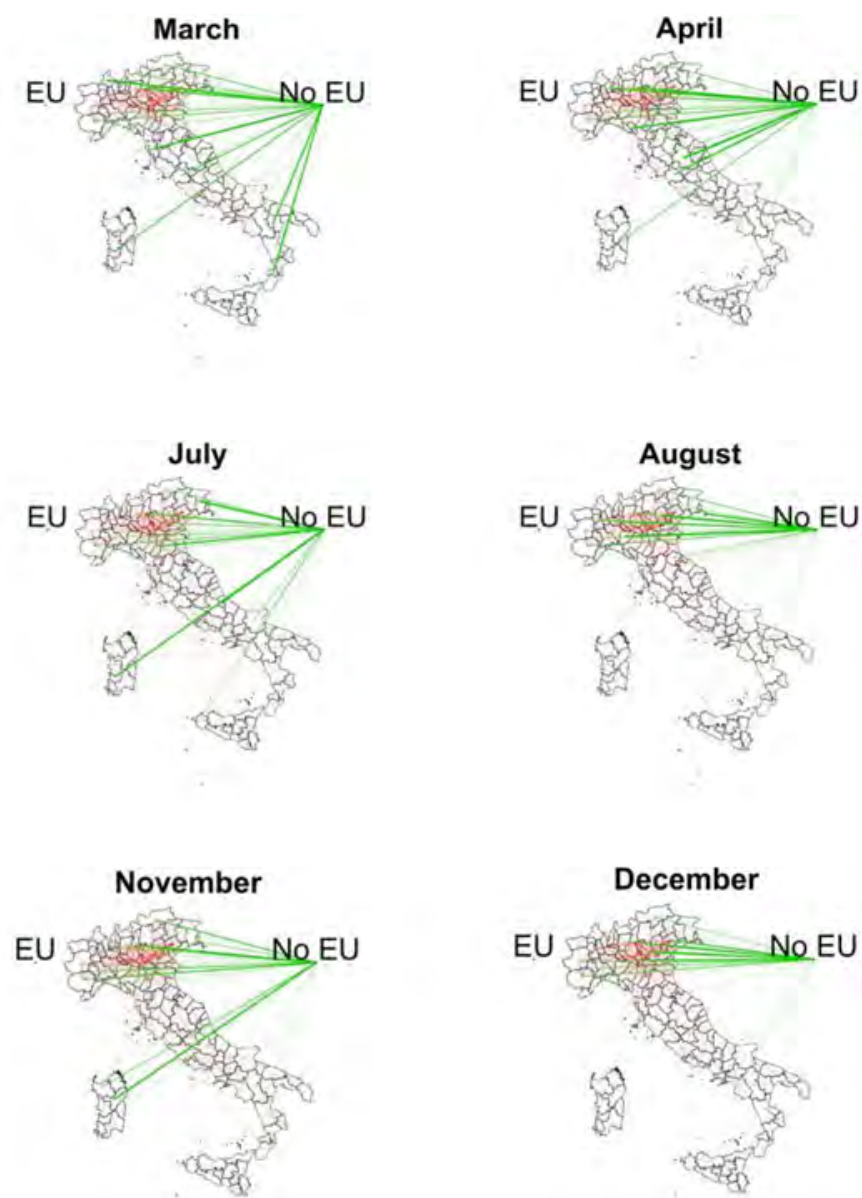

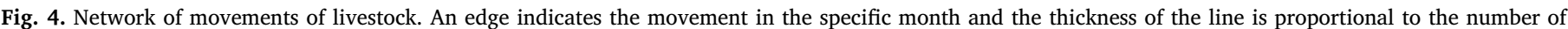

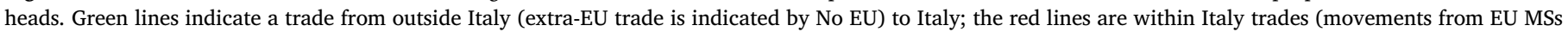

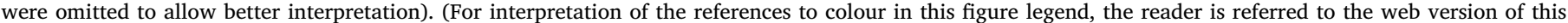
article.)

Italy in Padova in July and August, but the probability in Sardinia and Sicily remain fairly high throughout the year.

The uncertainty relating to the probability of having an index case in the Italian livestock is shown by the scatterplots of Figs. 7 and 8, where two specific months of the year are represented (January and July respectively), considered as the two extremes in terms of temperature. Italianprovinces are shown on the $\mathrm{Y}$ axis.

Fig. 9 shows the map of the Italian BT outbreaks which occurred between the 1st of January 2016 and the 30th of April 2018. It can be seen that observed outbreaks of BT occurred most often in North Eastern Italy, but also in Sardinia, Sicily and a number of cases around Campania and Molise. In Fig. 10 the model estimates over the period April-October of the average probability of the introduction of the disease are shown either a) without the network analysis or b) with the network analysis. Comparing actual outbreaks in Fig. 9 to the model predictions in Fig. 10, shows that areas of southern Sardinia and eastern
Sicily are relatively high risk, compared to other provinces. The model without the network analysis did not predict relatively high risk anywhere else in Italy, while the model incorporating the network analysis predicted the highest risk to be in the North Eastern region of Italy, and also highlighted Salerno in Campania.

The sensitivity analysis (Fig. 11) revealed that the probability a vector becomes infected (C38, index value in Table $1 \mathrm{~b})$ and the vaccine coverage ( $\mathrm{C} 18$, index value in Table $1 \mathrm{~b})$ as the parameters which had the greatest weight in the model. Temperature (C2, index value in Table $1 \mathrm{~b}$ ) was the parameter with the third highest $\mathrm{F}$ value. The probability that a vector becomes infected is of most concern as while temperature and vaccination are reasonably well parameterised, there is high uncertainty surrounding the probability a vector becomes infected due to limited data availability. 

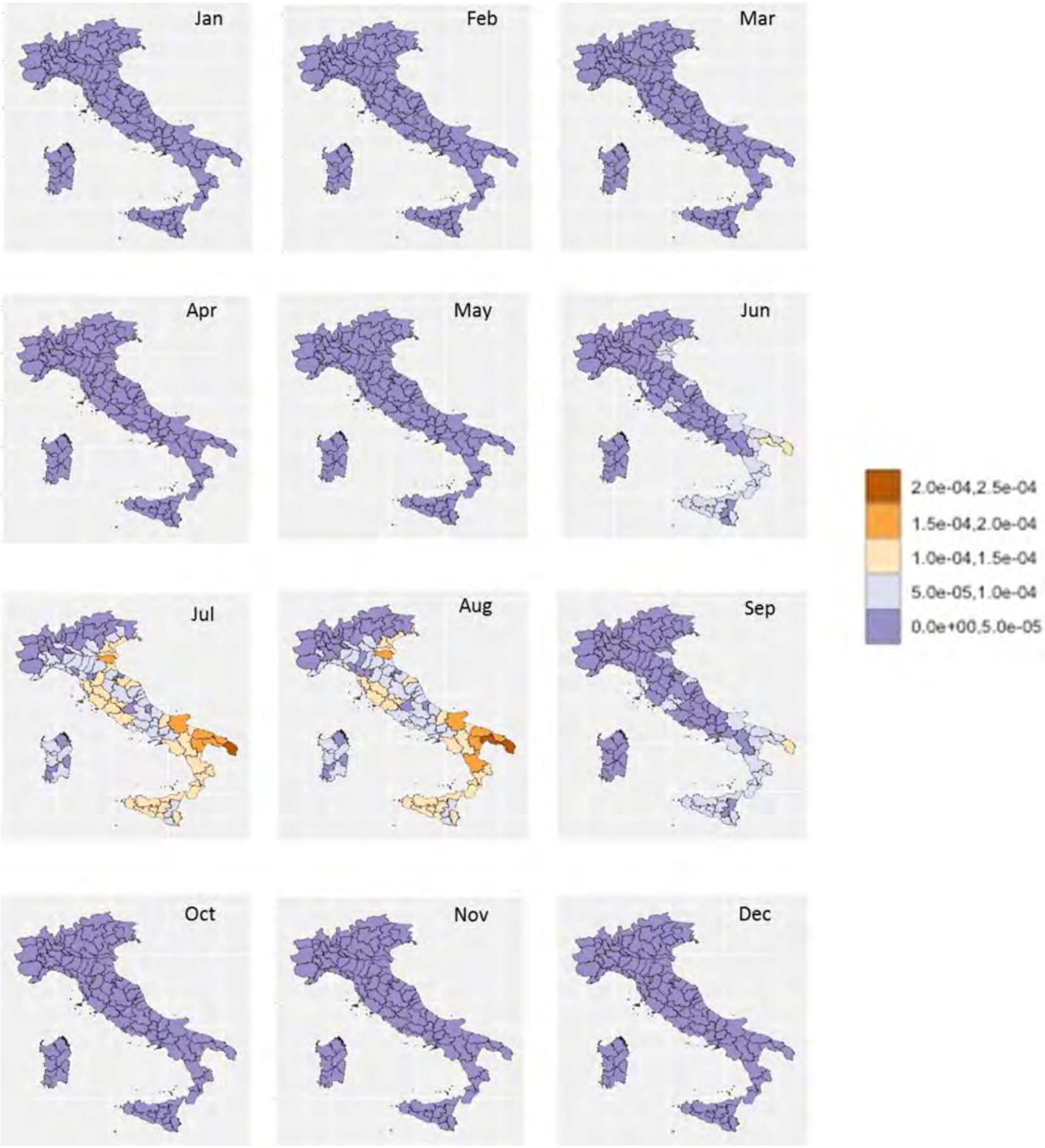

Fig. 5. The maps show the median value of $P_{v i r, j, h}$, that is, the probability of having an infected autochthonous case given that there is an infected imported vector. The legend shows the absolute risk split in equal size categories; brown represents the highest risk, whereas blue represents the lowest risk. (For interpretation of the references to colour in this figure legend, the reader is referred to the web version of this article.) 

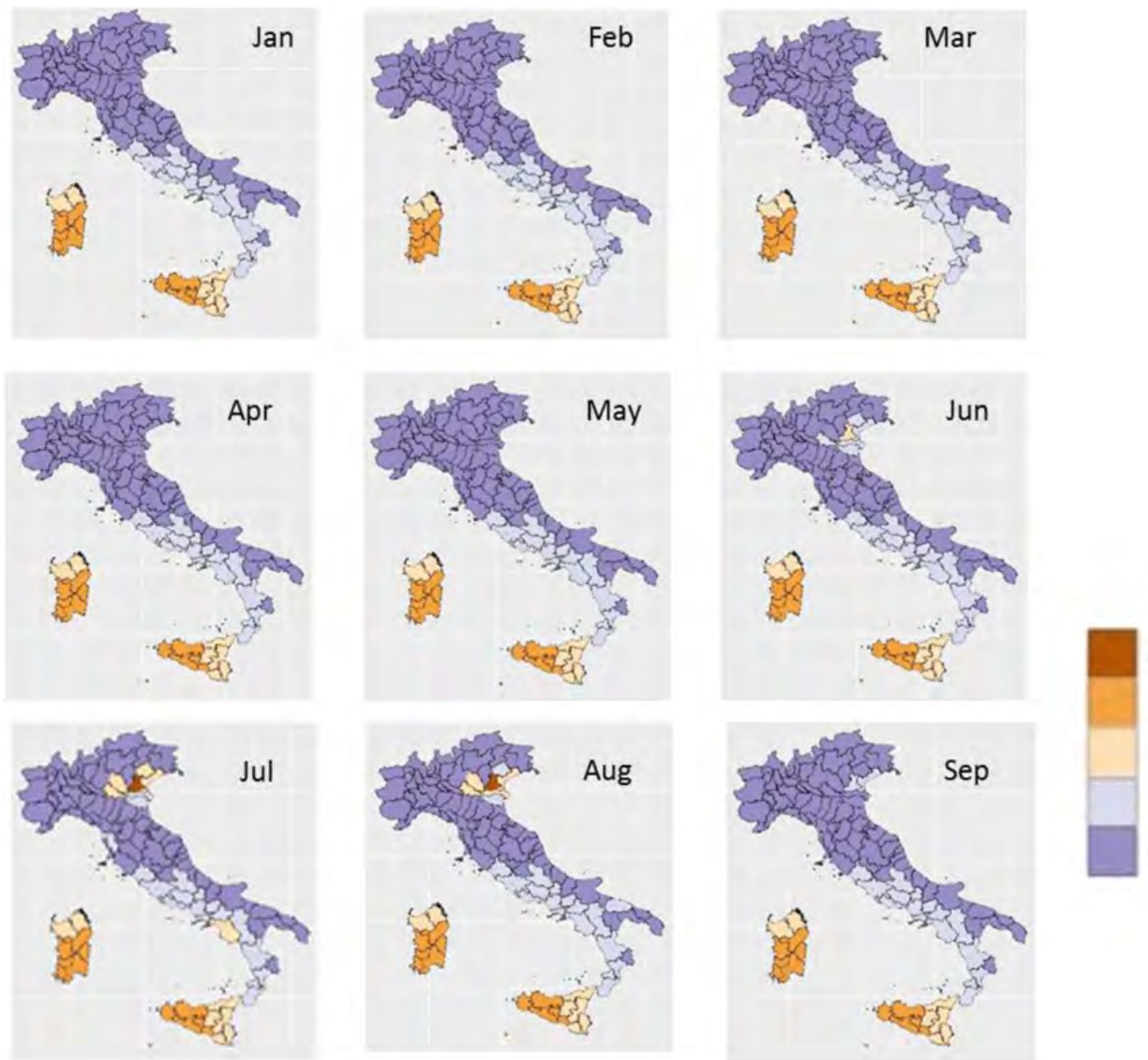

$6.8 \mathrm{e}-06,8.5 \mathrm{e}-06$

5. $1 \mathrm{e}-06,6.8 \mathrm{e}-06$

3.4e-06,5.1e-06

$1.7 \mathrm{e}-06,3.4 \mathrm{e}-06$

$0.0 e+00,1.7 e-06$
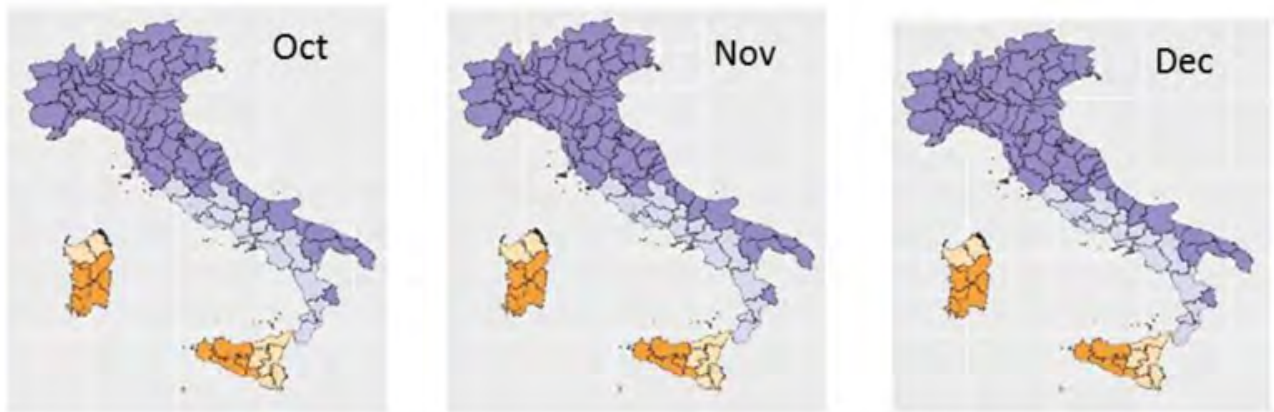

Fig. 6. The maps show the median value of $P_{\text {final }, j, \text { }}$, that is the probability of having an infected autochthonous case as the result of the model integrated with SNA. The legend shows the absolute risk split in equal size categories; brown represents the highest risk, whereas blue represents the lowest risk. (For interpretation of the references to colour in this figure legend, the reader is referred to the web version of this article.)

\section{Discussion}

Here, we have proposed a flexible model framework, adaptable to different animal diseases, for the spatial risk of an imported EAD which is useful to inform the preparedness of a Member State. The model was parameterised to assess the probability of onward transmission of BT virus, regardless of serotype, within individual Italian provinces. Our model estimated the probability of BT entering Italy with two different frameworks: one using a national probability, i.e. the same release probability for every Italian province, and the other one using SNA to 

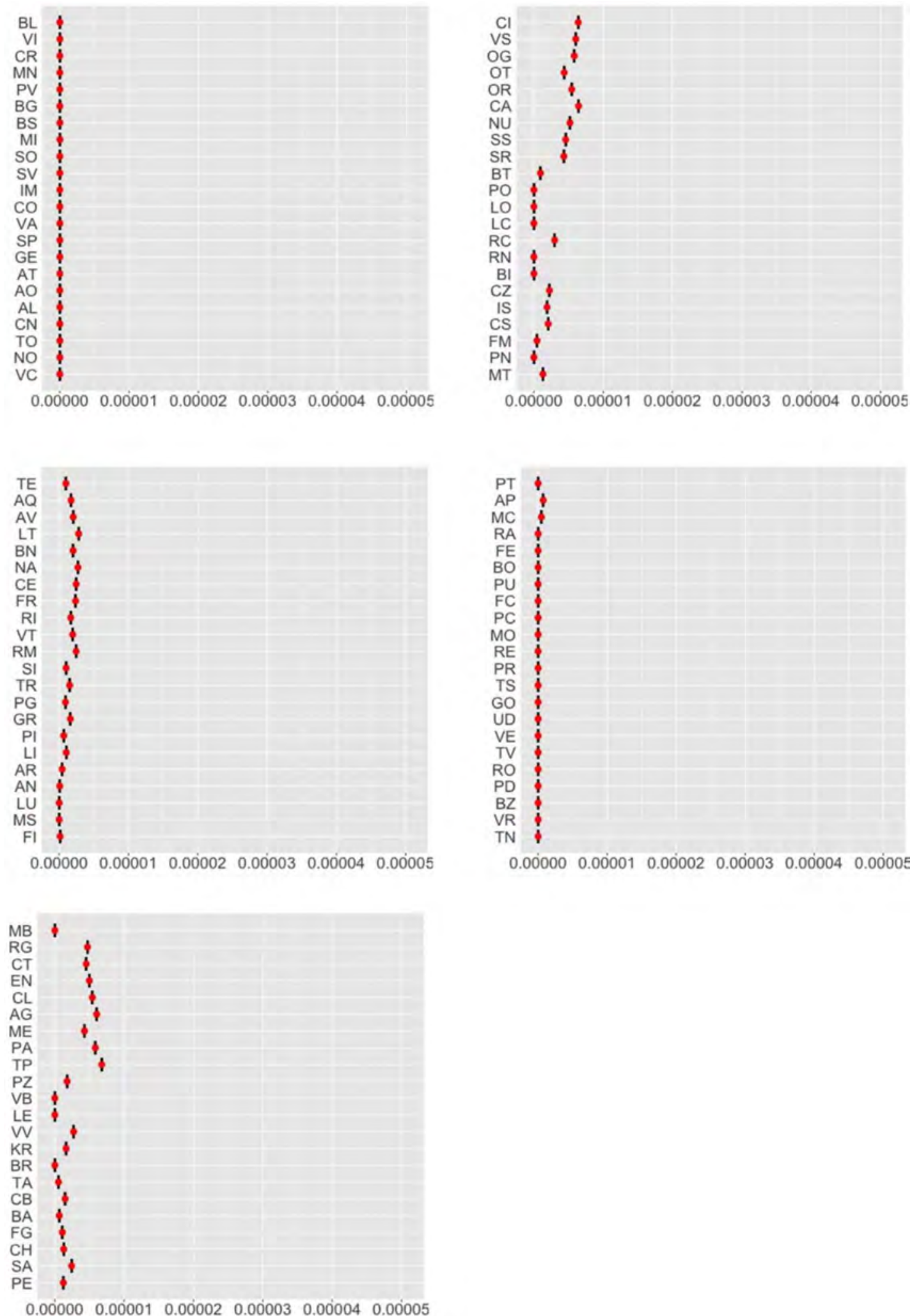

Fig. 7. Scatterplot of the mean value of the probability in January of at least one autochthonous case resulting from the introduction of at least one infected vector in an Italian province (red dot) and its 95\%CI (horizontal black line). Provinces are shown on the $\mathrm{Y}$ axis. (For interpretation of the references to colour in this figure legend, the reader is referred to the web version of this article.) 

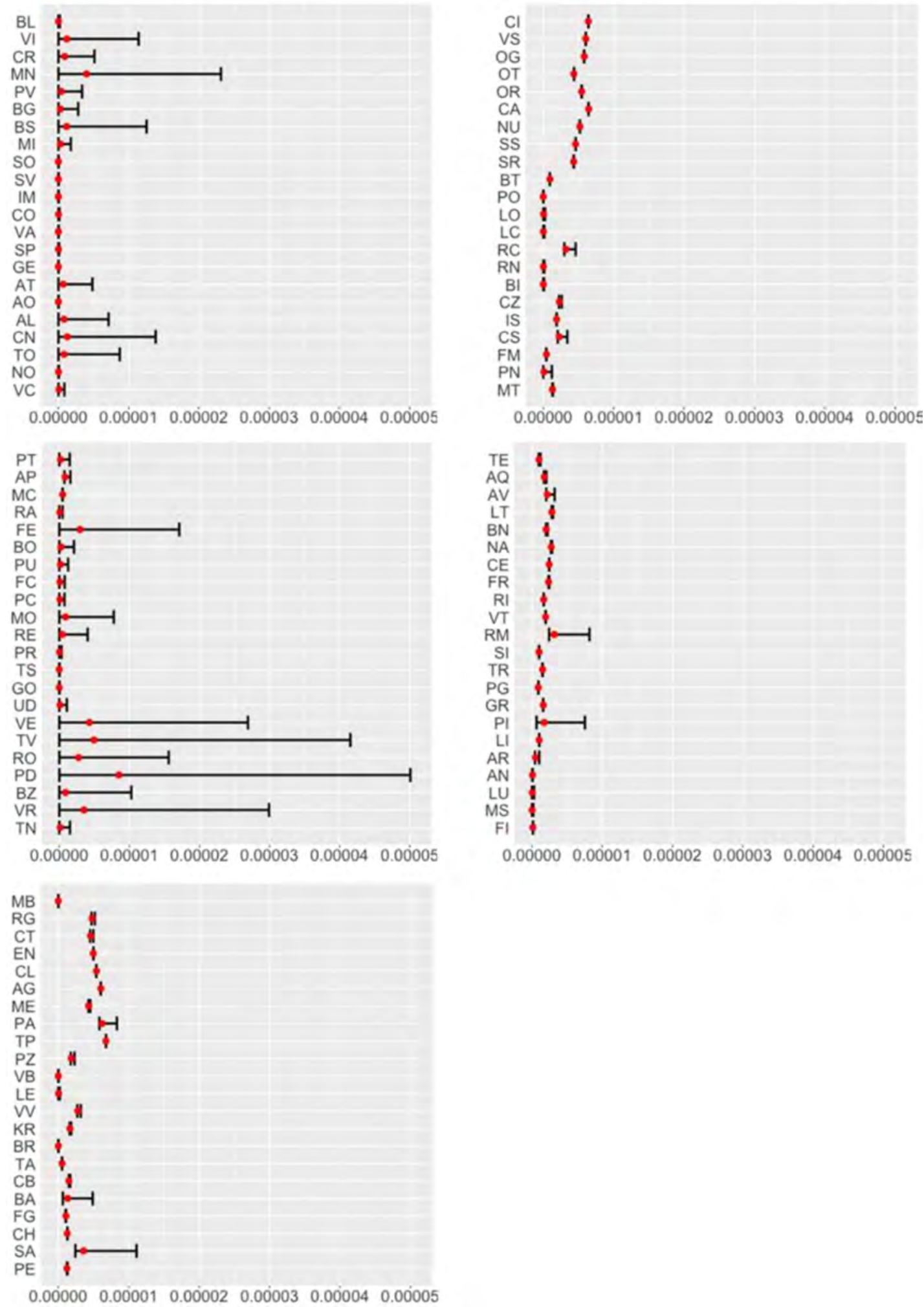

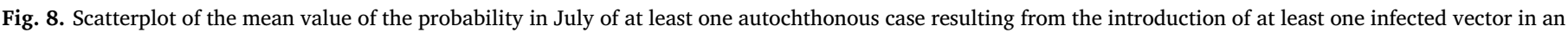

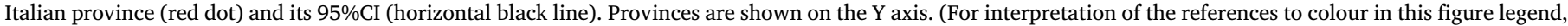
the reader is referred to the web version of this article.) 


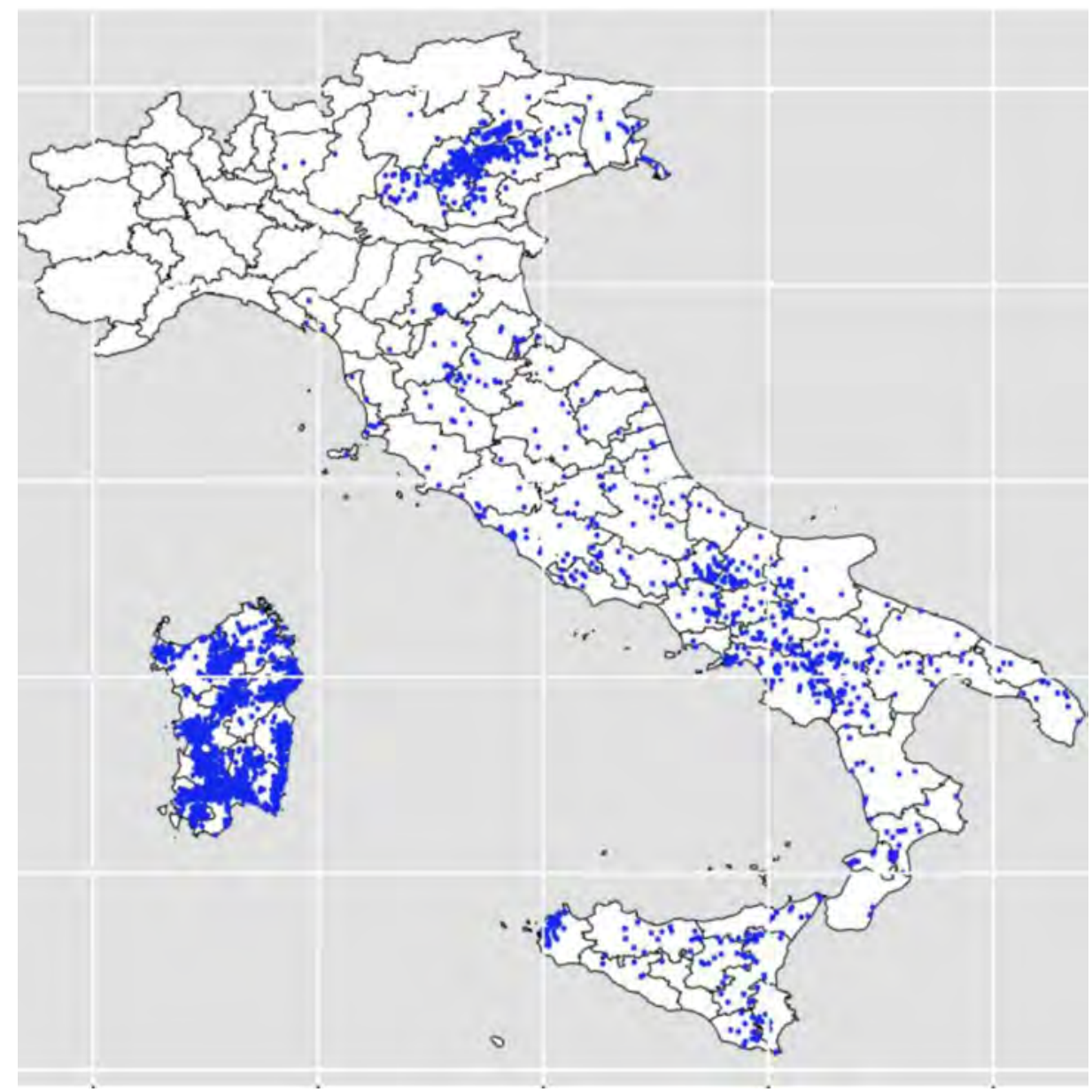

Fig. 9. Map of the BT outbreaks; each blue dot is a single BT outbreak, in any species and regardless of serotypes (1st of January 2016-30th of April 2018). (For interpretation of the references to colour in this figure legend, the reader is referred to the web version of this article.)

estimate differences in the release probability among provinces based on the relative frequency of livestock movements. In the exposure pathway, by considering the combination of several parameters (i.e. environmental features, animal susceptibility, livestock demography, movements and features regarding vectors ability to survive) we gave flexibility to the model which can be well adapted to other countries. By integrating an import risk assessment model with SNA, we were able to identify areas at higher risk of introduction of BT which, otherwise, would not have been evident.

Results of the risk of introduction of an infected vector, including SNA, suggest varying levels of risk among the different Italian provinces, and highlight the influence of trades and of distance from Africa on the whole model. Areas with the highest number of exchanges have been highlighted, both from EU and extra-EU. The network has been useful to better differentiate the level of risk among the Italian provinces by accounting for the number of animal movements in one single province. Maps resulting from the exposure pathway alone (i.e. without accounting for animal movements) show a remarkable homogeneity among the provinces which changes only during the warmest months (Fig. 4). Scatter plots drawn down to highlight the uncertainty around the mean values of probability show a high level of uncertainty only in some provinces and during the summer season.

Moreover, the southern regions, show a constant risk, along all the seasons, due to their proximity to North Africa. Conversely, the integration of SNA into the exposure assessment results in a larger heterogeneity of the risk by province. When integrating SNA into exposure assessment the risk given by the proximity to North Africa is reduced, because it is combined with the weight given to commercial exchanges among countries. As emphasised by other authors (Seimenis, 2008; Mintiens et al., 2008) commercial exchanges are an important risk factor for the introduction and/or spread of the infection over vast territories.

By comparing the observed data of BT outbreaks (Fig. 9) with the modelled prediction maps it is evident that the exposure assessment integrated with SNA (Fig. 10b) predicts outbreaks in a more reliable way. The North-Eastern area, where a lot of BT cases have been detected over the last two years, is not clearly identified by the exposure model without the SNA (Fig. 10a), whereas it is well drawn by the second model. The area in Campania, is also highlighted by considering SNA, but it is ignored by the exposure pathway alone. The network 

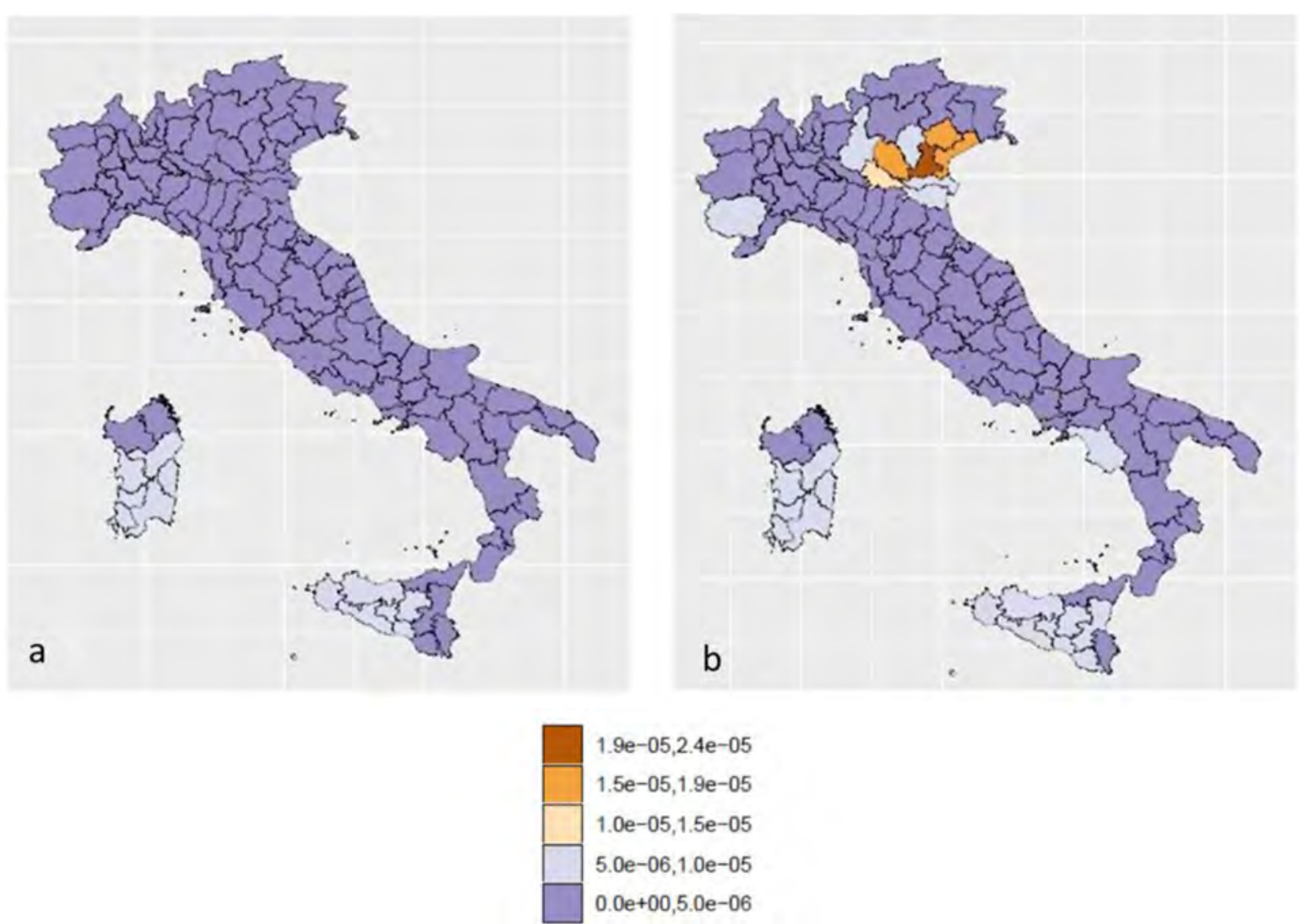

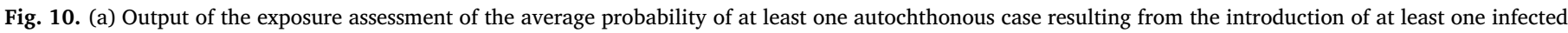

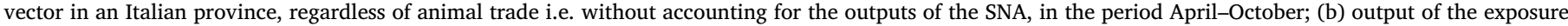

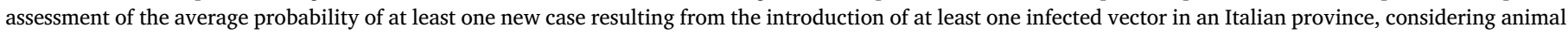
trades i.e. accounting for the additional information obtained through the SNA, in the period April-October.

model predicts also Cuneoin Piedmont (North-West of Italy) to have a risk of introduction of the disease even if low, but no outbreaks have been reported in this region. This prediction is likely due to the relatively large numbers of cattle movements into this region (Fig. 4). The lack of observed outbreaks suggests that there may be a protective factor associated with this region not considered by the model, perhaps the high altitude or lower temperature is inhospitable to the relevant midge species. With appropriate data, such factors could be introduced to the model in the future.

The ability to measure animal movements by SNA can allow the identification of areas where the risk of introduction is higher than in other zones; this could improve the effectiveness of a country's disease surveillance system. The outputs of this assessment, considering the uncertainties, can help to inform national surveillance policies, by providing evidence for geographical areas where livestock are more likely to be effectively exposed and to map the critical points within the trade network.

For instance, based on the results of such a model a risk-based surveillance system could be put in place, by identifying geographical hot spots. Risk-based surveillance systems offer a more efficient approach for early detection and management of diseases (Stärk et al., 2006) and can provide the basis for efficient resource allocation (Thornton, 2004). The core rationale underpinning risk-based strategies is that issues that present higher risks merit higher priority for surveillance resources as these investments will yield higher benefit-cost ratios (Stärk et al., 2006).

A further added value is derived from possibility of carrying out a sensitivity analysis. In our case study, the sensitivity analysis highlighted that vaccine coverage and the probability for a vector to become infected as the most important parameters of the model. As it is quite difficult to implement any barrier against midges becoming infected with BT, an extra effort in the vaccine campaign against BT virus could be a feasible strategy as an efficient control measure against the spread of the disease.

When animal movement data are available, it is possible to refine import risk assessment models by integrating them with SNA. Our model demonstrates how this can result in the opportunity for member States to optimise and target the surveillance measures to deal with EADs. 


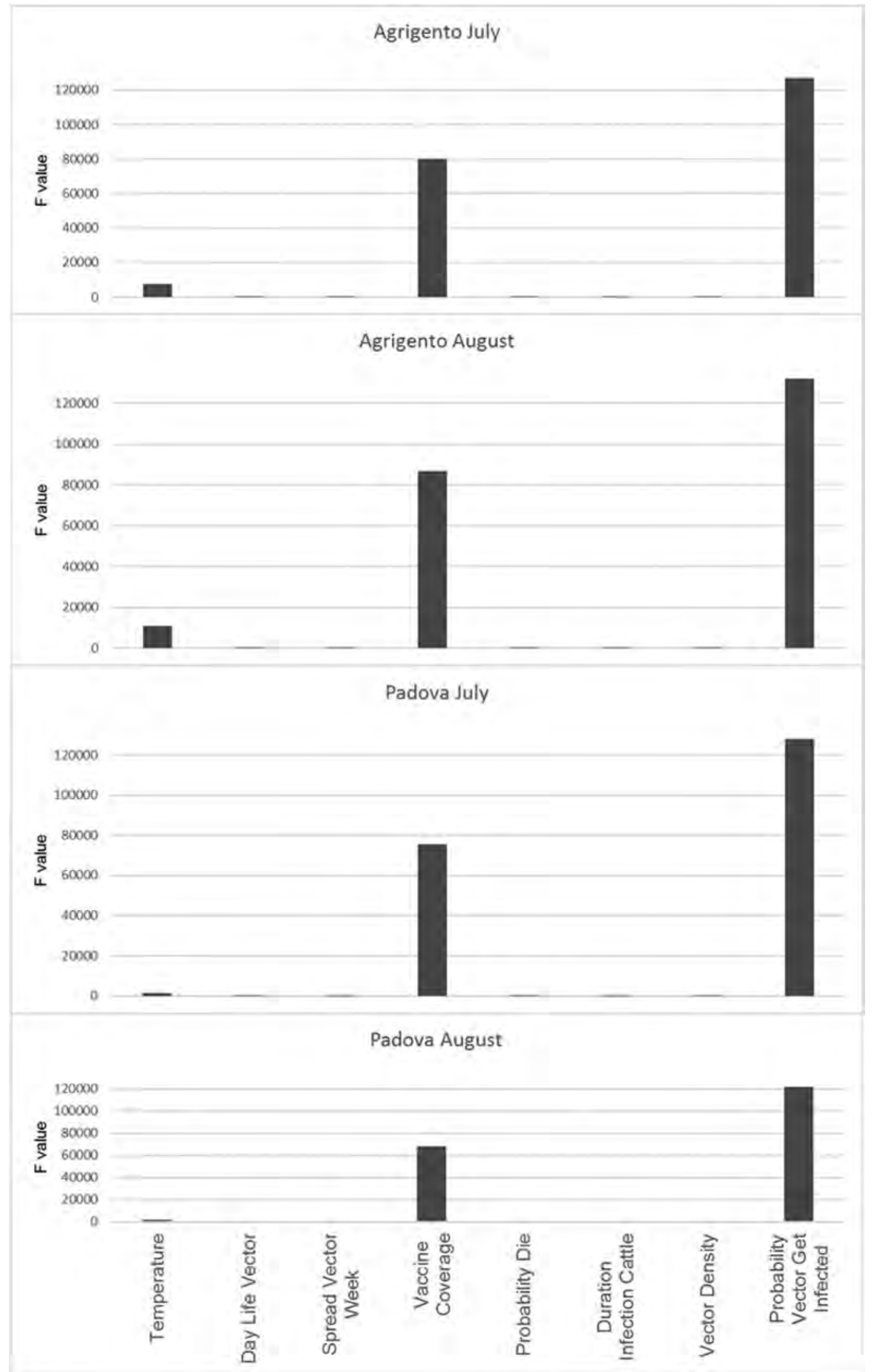

Fig. 11. Sensitivity analysis results for two provinces at high risk, Agrigento and Padova, and for the two months at highest risk, July and August as an illustration of the outputs. Model parameters (C2, C11, C12, C18, C22, C24, C25, C38 of Table 1b) are shown on the X axis and the associated F values on the Y axis. 


\section{Acknowledgements}

This work had funding agreed through the Animal Health and Welfare ERA-NET consortium (https://www.anihwa.eu/) under SPARE ('Spatial risk assessment framework for assessing exotic disease incursion and spread through Europe'). Funders are acknowledged as the Department for the Environment, Food and Rural Affairs (Defra) - UK, Ministry of Health - Italy, Spanish National Institute of Agriculture and Food Research and Technology - Spain, and Federal Food Safety and Veterinary Office (FSVO) - Switzerland.

\section{Conflict of interest}

The authors have no conflict of interest to declare.

\section{References}

Adkin, A., Brouwer, A., Downs, S.H., Kelly, L., 2016. Assessing the impact of a cattle riskbased trading scheme on the movement of bovine tuberculosis infected animals in England and Wales. Prev. Vet. Med. 123, 23-31.

Blancou, J., Chomel, B.B., Belotto, A., Meslin, F.X., 2005. Emerging or re-emerging bacterial zoonoses: factors of emergence, surveillance and control. Vet. Res. 36 (3), 507-522 May-Jun.

Bigras-Poulin, M., Thompson, R.A., Chriel, M., Mortensen, S., Greiner, M., 2006. Network analysis of Danish cattle industry trade patterns as an evaluation of risk potential for disease spread. Prev. Vet. Med. 76 (1-2), 11-39 Sep 15.

Fevre, E.M., Bronsvoort, B.M., Hamilton, K.A., Cleaveland, S., 2006. Animal movements and the spread of infectious diseases. Trends Microbiol. 14 (3), 125-131 Mar.

Frey, H.C., Patil, S.R., 2002. Identification and review of sensitivity analysis methods. Risk Anal. 22 (3), 553-578.

Gerry, A.C., Mullens, B.A., 2000. Seasonal abundance and survivorship of Culicoides sonorensis (Diptera: ceratopogonidae) at a southern California dairy, with reference to potential bluetongue virus transmission and persistence. J. Med. Entomol. 37, $675-688$.

Gilbert, M., Mitchell, A., Bourn, D., Mawdsley, J., Clifton-Hadley, R., Wint, W., 2005. Cattle movements and bovine tuberculosis in Great Britain. Nature 435 (7041), 491-496 May 26.

Giovannini, A., MacDiarmid, S., Calistri, P., Conte, A., Savini, L., Nannini, D., et al., 2004. The use of risk assessment to decide the control strategy for bluetongue in Italian ruminant populations. Risk Anal. 24 (6), 1737-1753 Dec.

Guis, H., Caminade, C., Calvete, C., Morse, A.P., Tran, A., Baylis, M., 2011. Modelling the effects of past and future climate on the risk of bluetongue emergence in Europe. J. R. Soc. Interface. https://doi.org/10.1098/rsif.2011.0255. Published online.

Hartemink, N.A., Purse, B.V., Meiswinkeld, R., Brownc, H.E., de Koeijer, A., Elbersd, A.R.W., Boender, G.-J., Rogers, D.J., Heesterbeek, J.A.P., 2009. Mapping the basic reproduction number (R0) for vector-borne diseases: a case study on bluetongue virus. Epidemics 1, 153-161.

King, L.J., Marano, N., Hughes, J.M., 2004. New partnerships between animal health services and public health agencies. Rev. Sci. Tech. 23 (2), 717-725 Aug.

Martinez-Lopez, B., Perez, A.M., Sanchez-Vizcaino, J.M., 2009. Social network analysis
Review of general concepts and use in preventive veterinary medicine. Transbound. Emerg. Dis. 56 (4), 109-120 May.

Mintiens, K., Meroc, E., Faes, C., Abrahantes, J.C., Hendrickx, G., Staubach, C., et al., 2008. Impact of human interventions on the spread of bluetongue virus serotype 8 during the 2006 epidemic in north-western Europe. Prev. Vet. Med. 87 (1-2), 145-161 Oct 15.

Natale, F., Giovannini, A., Savini, L., Palma, D., Possenti, L., Fiore, G., et al., 2009. Network analysis of Italian cattle trade patterns and evaluation of risks for potential disease spread. Prev. Vet. Med. 92 (4), 341-350 Dec 1.

Noremark, M., Hakansson, N., Lewerin, S.S., Lindberg, A., Jonsson, A., 2011. Network analysis of cattle and pig movements in Sweden: measures relevant for disease control and risk-based surveillance. Prev. Vet. Med. 99 (2-4), 78-90 May 1.

Nunamaker, R.A., Mecham, J.O., Wigington, J.G., Ellis, J.A., 1997. Bluetongue virus in laboratory-reared Culicoides variipennis sonorensis: applications of dot-blot, ELISA, and immunoelectron microscopy. J. Med. Entomol. 34 (1), 18-23.

Nurminen, M., Nurminen, T., Corvalan, C.F., 1999. Methodologic issues in epidemiologic risk assessment. Epidemiology. 10 (5), 585-593 Sep.

O.I.E., 2012. Risk Analysis. Terrestrial Animal Health Code, twelfth ed. World Animal Health Organisation, Paris, pp. 73-78.

O.I.E. WAHIS Interface 2016b. Available from: http://www.oie.int/wahis_2/public/ wahid.php/Wahidhome/Home.

Patil, S.R., Frey, H.C., 2004. Comparison of sensitivity analysis methods based on applications to a food safety risk assessment model. Risk Anal. 24 (3), 573-585.

Peeler, E.J., Reese, R.A., Thrush, M.A., 2015. Animal disease import risk analysis-a review of current methods and practice. Transbound Emerg. Dis. 62 (5), 480-490 Oct.

Roberts H., Moir R., Matt C., Spray M., Boden L., Bessell P. Risk assessment for Bluetongue Virus (BTV-8): risk assessment of entry into the United Kingdom (2016) (https:// www.gov.uk/government/publications/qualitative-risk-assessment-bluetonguevirus-btv-8-entry-into-the-uk).

Savini, G., Goffredo, M., Monaco, F., Di Gennaro, A., Cafiero, M.A., Baldi, L., De Santis, P. Meiswinkel, R., Caporale, V., 2005. Bluetongue virus isolations from midges belonging to the Obsoletus complex (Culicoides, Diptera: ceratopogonidae) in Italy. Vet. Rec. 157, 133-139.

Sellers, R.F., 1992. Weather, Culicoides, and the distribution and spread of bluetongue and African horse sickness viruses. In: Walton, T.E., Osburn, B.I. (Eds.), Bluetongue, African Horse Sickness, and Related Orbiviruses. CRC, Boca Raton, FL, pp. 1042.

Seimenis, A.M., 2008. The spread of zoonoses and other infectious diseases through the international trade of animals and animal products. Vet Ital. 44 (4), 591-599 OctDec.

Simons, R., Horigan, V., Gale, P., Kosmider, R., Breed, A., Snary, E., 2016. A generic quantitative risk assessment framework for the entry of bat-borne zoonotic viruses into the European Union. PLoS One 11 (10), e0165383.

Simons R.R.L., Horigan V., I.p. Sophie, Taylor R.A., Crescio M.I., Maurella C., Mastrantonio G., Bertolini S., Ru G., Cook C., Adkin A., 2019. A spatial entry assessment model framework for incursion of exotic disease into the European Union (SPARE). Under second revision in this journal.

Stärk, K.D., Regula, G., Hernandez, J., Knopf, L., Fuchs, K., Morris, R.S., Davies, P., 2006. Concepts for risk-based surveillance in the field of veterinary medicine and veterinary public health: review of current approaches. BMC Health Serv. Res. 6, 20. https://doi. org/10.1186/1472-6963-6-20.

Thornton, R., 2004. Ambitious domesticated animal surveillance review initiated. Biosecur. Issue 51, 6-7.

Walsh, A.L., Morgan, D., 2005. Identifying hazards, assessing the risks. Vet. Rec. 157 (22), 684-687 Nov 26. 